
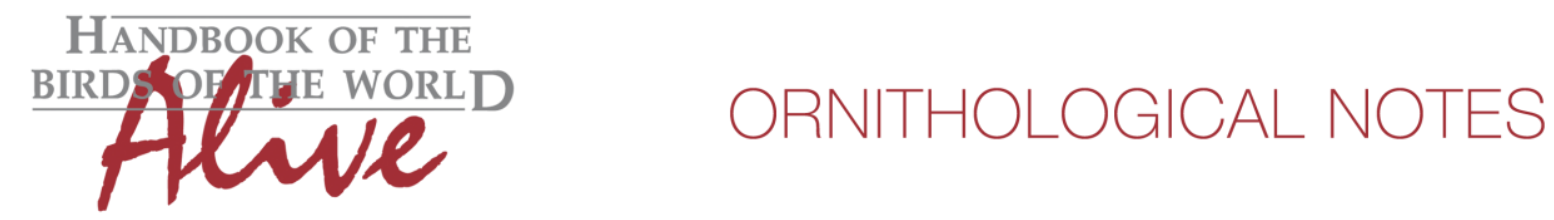

\title{
Notes on the vocalizations of Arabian Magpie (Pica asirensis)
}

Peter Boesman

In the following we briefly analyze and compare voice of Arabian Magpie (Pica asirensis) with Eurasian Magpie (Pica pica). We also try to quantify the extent of any vocal differences using the criteria proposed by Tobias et al. (2010), as a support for taxonomic review.

We have made use of sound recordings available on-line from Xeno Canto (XC).

The HBW Alive voice description reads: Calls very different from those of $P$. pica. Three types of call described: a full, loud "quaynk-quaynk" given from top of bush or when a party is on the move; weaker "quenk, quenk" when bird alarmed or stressed during foraging; and soft "qua, qua" by food-begging young. Seems to be very vocal, group-members keeping in contact as they forage.

We have only found a single recording on-line of $P$. asirensis. This vocalization can be described as an upslurred drawn-out quite nasal and high-pitched note repeated a few times, quite different from any usual vocalization of $P$. pica in Europe, and this fits quite well the HBW description.

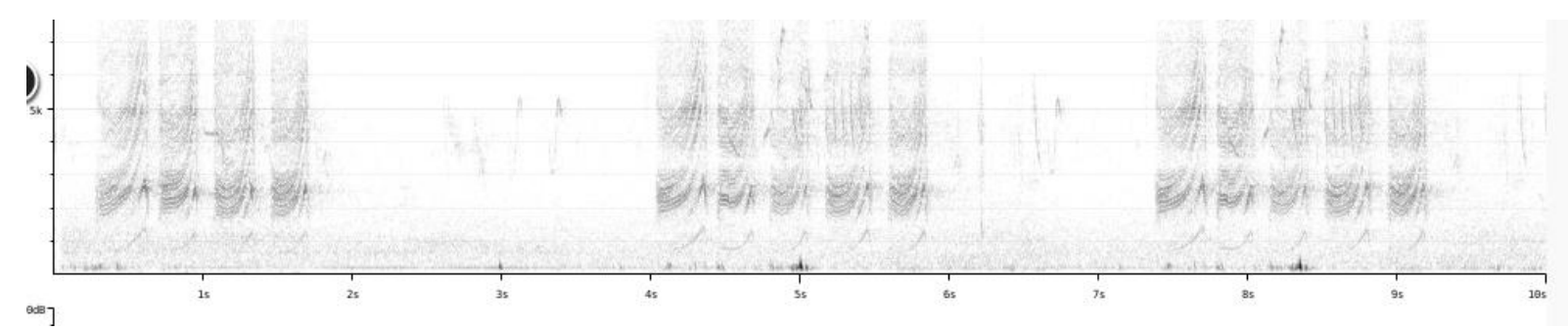

By looking into the 290 available XC recordings of $P$. pica, we checked if there is any close match to this vocalization. We found only a single similar vocalization, of race bactriana:

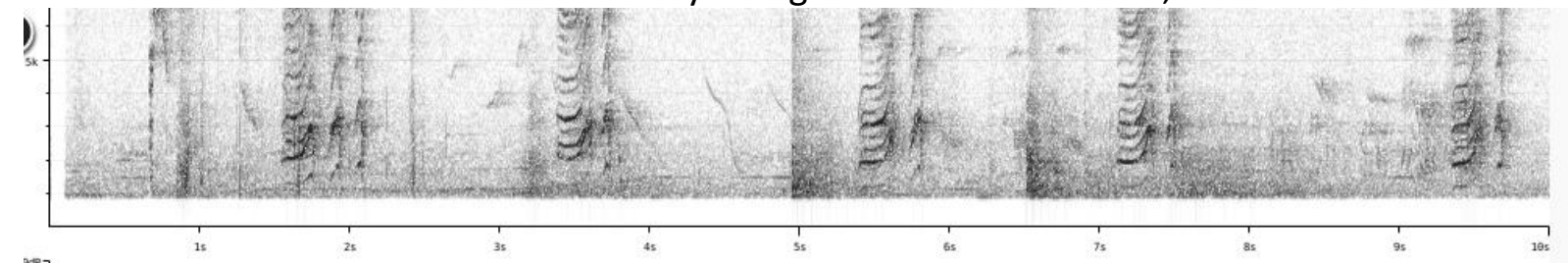

All other available recordings of race bactriana are more 'typical pica-like'.

It is not really surprising that exactly race bactriana is found to share a (similar) vocalization with $P$. asirensis, as it is closest to the latter geographically.

With only a single recording of asirensis, we can't draw any firm conclusions.

A possibility is that asirensis originated from bactriana, and started using this particular vocalization almost exclusively. 

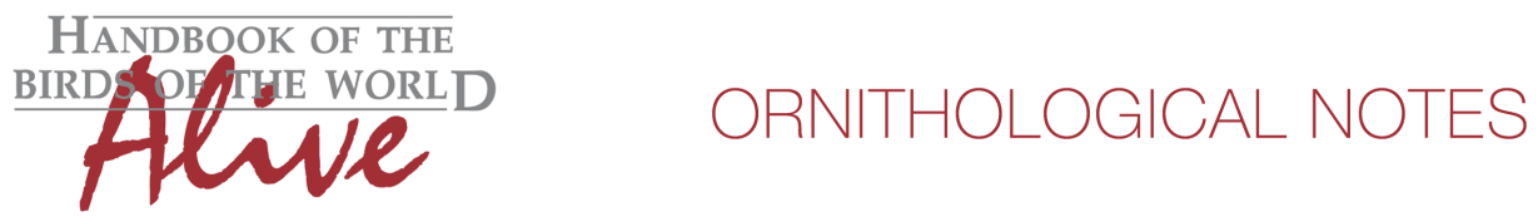

If asirensis mainly utters this particular vocalization (as suggested in HBW Alive), then we have a case somewhat similar to e.g. the Sirystes case, where a split into four species was defended based on the frequency with which certain vocalization types are uttered, and where it was put forward that even in the case a certain vocalization is shared, through evolution that particular sound may have acquired a different function in communication.

All in all, with the weak evidence, but with confirmation of voice description in HBW Alive, it would seem that there is indeed a vocal difference, which for now we estimate to be about score 3. More recordings are needed to confirm this.

This note was finalized on 27th January 2016, using sound recordings available on-line at that moment. We would like to thank in particular the many sound recordists who placed their recordings for this species on XC, and in particular Khalifa Al Dhaheri for the asirensis recording.

\section{References}

Madge, S. (2016). Arabian Magpie (Pica asirensis). In: del Hoyo, J., Elliott, A., Sargatal, J., Christie, D.A. \& de Juana, E. (eds.). Handbook of the Birds of the World Alive. Lynx Edicions, Barcelona. (retrieved from http://www.hbw.com/node/60754 on 27 January 2016).

Tobias, J.A., Seddon, N., Spottiswoode, C.N., Pilgrim, J.D., Fishpool, L.D.C. \& Collar, N.J. (2010). Quantitative criteria for species delimitation. Ibis 152(4): 724-746.

\section{Recommended citation}

Boesman, P. (2016). Notes on the vocalizations of Arabian Magpie (Pica asirensis). HBW Alive Ornithological Note 206. In: Handbook of the Birds of the World Alive. Lynx Edicions, Barcelona. (retrieved from http://www.hbw.com/node/932154 on 2 September 2016). 